Portland State University

PDXScholar

\title{
Determinants of Substance Abuse among Incarcerated Adolescents: Implications for Brief Treatment and Crisis Intervention
}

\author{
Stephen J. Tripodi \\ University of Texas, Austin \\ David W. Springer \\ University of Texas, Austin \\ Kevin Corcoran \\ Portland State University
}

Follow this and additional works at: https://pdxscholar.library.pdx.edu/socwork_fac

Part of the Social Work Commons

Let us know how access to this document benefits you.

\section{Citation Details}

Determinants of substance abuse among incarcerated adolescents: Implications for brief treatment and crisis intervention. Brief Treatment and Crisis Intervention, 7, 34-39.

This Article is brought to you for free and open access. It has been accepted for inclusion in School of Social Work Faculty Publications and Presentations by an authorized administrator of PDXScholar. Please contact us if we can make this document more accessible: pdxscholar@pdx.edu. 


\title{
Determinants of Substance Abuse Among Incarcerated Adolescents: Implications for Brief Treatment and Crisis Intervention
}

\author{
Stephen J. Tripodi, MSSW \\ David W. Springer, PhD \\ Kevin Corcoran, PhD, JD
}

\begin{abstract}
This study assessed the determinants of substance abuse among incarcerated youth. Because substance abuse is a predictor of incarceration and conduct disorder is known to increase the chances of youth abusing substances, the purpose of this study was to determine what seminal symptoms of conduct disorder seem to be the risk factors for substance abusers among incarcerated youth. Data were collected on 83 youth in southern Oregon, 74 males and 9 females. Logistic regression found the overall model containing 6 symptoms of conduct disorder to be significantly related to substance abuse $(p<.001)$. When looking at the 6 symptoms individually, however, only running away from home was significantly related to substance abuse $(p<.001)$. Incarcerated youth who reported running away from home were more than 9 times likely to abuse substances than incarcerated youth who did not report running away from home. This indicates the importance of conducting brief therapy for the prevention and intervention of youth running away from home. The article concludes with a discussion on the importance of assessments, treatment plans, and conducting the harm-reduction approach. [Brief Treatment and Crisis Intervention 7:34-39 (2007)]
\end{abstract}

KEY WORDS: incarcerated adolescents, substance abuse, runaway, brief treatment.

Although juvenile crime is at a 20-year low (Synder, 2002), the prevalence of young offenders remains astonishingly high at approximately $10 \%$ of American youth (Federal Bureau of Investigation, 2000; Synder, 2000, 2002).

From the School of Social Work, University of Texas, Austin (Tripodi, Springer) and the School of Social Work, Portland State University (Corcoran).

Contact author: Stephen J. Tripodi, Doctoral Candidate, University of Texas at Austin, School of Social Work, 1 University Station D3500, Austin, TX 78712. E-mail: stripodi@mail.utexas.edu.

doi:10.1093/brief-treatment/mhl017

Advance Access publication November 28, 2006
One of the most common characteristics of young offenders is substance abuse (Office of Juvenile Justice and Delinquency Prevention, 1999), a fact fairly well established for almost three decades (Hirschi, 1969). For example, approximately $50 \%$ of incarcerated youth acknowledge using drugs or alcohol at the time of their wrongdoing (Bilchik as cited in DeMatteo \& Marczyk, 2005). As DeMatteo and Marczyk (2005) discuss, the nexus of substance abuse and crime is clearly there, but it may not be a simple cause-and-effect or even correlational relationship. They note that substance abuse is more likely a contributor to the

(c) The Author 2006. Published by Oxford University Press. All rights reserved. For permissions, please e-mail: journals.permissions@oxfordjournals.org. 
continuation of offending but not necessarily to the onset of delinquency. And yet, it is persuasive to assert that substance abuse is a predictor of serious and persistent delinquency (DeMatteo \& Marczyk, 2005).

But what determines substance abuse among serious delinquents? In other words, if substance abuse is a risk factor in serious offending, then knowing the risk factors for substance abuse would aid not only treatment of offenders but also perhaps prevention as well. As Hawkins, et al. (2000) observe, violent and chronic offending by juveniles may very well be the result of multiple risk factors, whereas multiple protective factors may thwart this type of antisocial behavior (Hanna as cited in DeMatteo \& Marczyk, 2005). Furthermore, Teplin, Abram, McClelland, Duclan, and Mericle (2003) conducted an epidemiological study to examine psychiatric disorders in 1,800 juvenile delinquents in Cook County, Illinois. They found that the most common disorders were substance-use disorders and disruptive behavior disorders, such as oppositional defiant disorder and conduct disorder.

Accordingly, the purpose of this study was to determine what seminal symptoms of conduct disorder seem to be the risk factors for substance abuse among incarcerated youth, whom we consider to be serious offenders.

\section{Methodology}

\section{Research Participants and Procedures}

Data were collected on a sample of 83 youth confined to a secured facility in southern Oregon. The maximum capacity was 97 youth, of which the sample represents $86 \%$. Youth were remunerated $\$ 2.00$ for completing the questionnaire with the funds being used for a correctional program activity; in particular, a grilled steak dinner. The research participants did not receive the money directly due to a policy prohibiting having items of pecuniary value.
The facility housed nine female offenders and 74 males. The average age of the sample was 16.3 years $(S D=1.4)$, which was not distinguishable by gender $(t<1.0)$. The majority was either European Americans (54\%) or Native Americans (26\%), and there was 11\% Hispanic Americans and only one African American.

\section{Instrumentation}

The independent variables were six critical symptoms of conduct disorder: setting fires, threatening others, torturing animals, destroying property, having carried a handgun, and running away. Five of these variables were derived from the Oregon Mental Health Referral Checklist (Corcoran, 2005) with the participants' endorsement of the presence or absence of the symptoms within 6 months prior to incarceration. The carrying of a handgun was defined by an item from the survey of Arthur, Hawkins, Catalano, and Pollard (n.d.) or by risk and protective factors. The item was a continuous variable, which was dichotomized for similarity with the other independent variables. Academic failure, family attachment, and family discipline were also ascertained from the risk and protective factors instrument.

The dependent variable was also derived from the Oregon Mental Health Referral Checklist and was the presence or absence of substance abuse 6 months prior to incarceration.

\section{Results and Discussion}

Logistic regression was used to determine the impact of the six criteria of conduct disorder and substance abuse. Logistic regression allows for the combination of the independent variables to estimate the probability that a particular event will occur (i.e., substance abuse). Furthermore, logistic regression is a robust procedure that does not assume normalcy, linearity, and homogeneity of variance for the 
TABLE 1. Variables in the Equation

\begin{tabular}{lrrrrrr} 
& $\boldsymbol{B}$ & SE & Wald & $\boldsymbol{d f}$ & Significance & $\operatorname{Exp}(\boldsymbol{B})$ \\
\hline Set fires & -0.374 & .652 & 0.329 & 1 & .566 & 0.688 \\
Threatened others & 0.145 & .689 & 0.044 & 1 & .833 & 1.156 \\
Tortured animals & -1.077 & .721 & 2.234 & 1 & .135 & 0.341 \\
Destroyed property & 0.323 & .733 & 0.194 & 1 & .660 & 1.381 \\
Runs away & 2.200 & .662 & 11.034 & 1 & .001 & 9.028 \\
Carried handgun & 0.241 & .166 & 2.115 & 1 & .146 & 1.273 \\
\hline
\end{tabular}

independent variables. The minimum sample needed for logistic regression is 10 cases per independent variable (Hair, Black, Babin, Anderson, \& Tatham, 2005). The sample size of 74 cases met this requirement for the six predictor variables, even though 20 cases per variable are preferable.

Using the criteria of studentized residuals greater than \pm 2.0 , there were no outliers in the sample, allowing for the analytic sample to be 84. As for multicollinearity (i.e., when two independent variables are so highly correlated that they are indistinguishable) the data suggest that this had not occurred. With no standard error greater than 2.0, all the six independent variables were consequently entered into the logistic regression model. Table 1 displays the standard error for each of the predictor variables.

In logistic regression, the presence of a relationship between the dependent and combination of independent variables is based on a statistically significant model of chi-square after the independent variables have been added to the analysis. The results were significant for the sample of 84 youth, $\chi^{2}=22.3, p<.001$. Thus, the null hypothesis that there is no difference between the model without the criteria of conduct disorder and the model with the criteria of conduct disorder is rejected.

To examine the relationships between the individual criterion of conduct disorder and substance abuse, we analyzed the significance of the Wald test of the beta coefficient and the in- terpretation of the odds ratio. Running away from home was the only individual characteristic of conduct disorder that was significantly related to substance abuse (Wald $=11.0, p<$ $.01)$. The value of $\exp (B)$ for running away was 9.03, which was statistically significant $(p<.001)$. This statistic indicates that those incarcerated youth who reported running away were nine times more likely to be substance abusers than youth who had not run away prior to their incarceration.

In this analysis the independent variables are characterized as useful predictors distinguishing incarcerated youth who are substance abusers from youth who are not abusing, if the classification accuracy is $25 \%$ or higher than the proportionality by chance alone. The proportionality by chance accuracy rate in this analysis was .53, and the classification accuracy rate was .72. The classification accuracy exceeds that due to chance, which suggests that the logistic model is a useful model.

In summary, these results suggest that incarcerated adolescent offenders with a history of running away are substantively more likely to abuse substances than their incarcerated counterparts without a history of running away. Adolescents who run away from home generally lack parental attachment and are truant from school, both of which are associated with low self-control and an increase in criminal wrongdoing (Gottfredson \& Hirschi, 1990; Martin, Tobin, \& Sugai, 2002). Similar results were found for the current sample, with running 
away significantly associated with academic failure $(r=.25, p<.05)$ and family discipline $(r=.26, p<.05)$ but was not associated with family attachment ( $r=-.03$, not significant). Because a lack of parental attachment and truancy are both positively associated with substance abuse and substance abuse is a predictor of juvenile delinquency, it is important to intervene with the young runaway as quickly as possible. From the perspective of young offenders, early intervention may provide structure and a foundation of support that could result in the young offender spending less time with their peer group, which has been associated with a reduction in juvenile crime (Warr, 2002).

\section{Implications for Brief Treatment and Crisis Intervention}

The key finding from this study is that incarcerated youth who reported a history of running away were nine times more likely to report abusing substances than their incarcerated counterparts who did not report a history of running away. Recall that the dependent variable in this study was the presence or absence of substance abuse 6 months prior to incarceration; accordingly, while the data were collected from incarcerated youth, the implications for brief treatment and crisis intervention from these findings will focus on efforts aimed at such youth while they are still on (or returned back to) the streets.

Runaway and homeless youth are generally "very involved in 'street economies,' peer networks, and "street culture" (Thompson, McManus, \& Voss, 2006, p. 207), and it is critical that helping professionals possess a healthy respect and appreciation for the personalenvironmental transactions between the runaway youth and these multilayered social contexts. Runaway and homeless youth themselves report that substance use is encouraged within the culture of the streets (Thompson et al., 2006). With this street culture and our key finding in mind, we make the following three recommendations for practice and policy.

First, youth presenting with multiple risk factors for incarceration (cf. Hawkins et al., 2000) should be assessed for their risk of running away from home. If incarcerated youth with a history of running away are nine times more likely to report abusing substances, then it stands to reason that when appropriate it may be worthwhile to prevent them from running away. The Triage Assessment Form (Myer, Williams, Ottens, \& Schmidt, 1992) has been recommended as a useful assessment tool for helping professionals working with youth in crisis (Springer, 2001), as it is based on a crisis assessment model of intervention where the goal is to help the client prioritize and mobilize resources (Myer, 2001). The Adolescent Concerns Evaluation, a 40-item pencil-and-paper scale that measures the degree to which a youth may be at risk of running away, may also be useful to this end (Springer, 1998, 2000).

Second, an ecologically grounded and integrated treatment plan, one that is developmentally and culturally sensitive and that addresses multiple risk factors concurrently, should be used. We began this article by citing a research that demonstrates that violent and chronic offending by juveniles may very well be the result of multiple risk factors. To this, we now add our finding that running away is a strong predictor of substance abuse among incarcerated juvenile offenders. Thus, both incarcerated and runaway youth present with multiple risk factors, and these risk factors seem to be correlated with substance abuse. Prospective studies that are able to examine putative risk and protective factors for this population are needed, as we need more sophisticated and accurate etiological models that in turn can inform primary, secondary, and tertiary prevention efforts. In the meantime, a 
multipronged approach that addresses these risk factors concurrently seems warranted.

Finally, we recommend the adoption of a harm-reduction approach. This strategy promotes public health rather than the criminal justice perspective when determining what to do with substance-abusing offenders (McNeece, Bullington, Arnold, \& Springer, 2005). Applied to substance-abusing incarcerated male youth with a history of running away, a population with its fair share of risk factors and environmental stressors, a harm-reduction (rather than a criminalized) approach might be a more sophisticated and nuanced lens through which to view and help this population. Policy makers and legislators are encouraged to prioritize treatment over incarceration.

\section{Acknowledgment}

Conflict of Interest: None declared.

\section{References}

Arthur, M. W., Hawkins, J. D., Catalano, R. F., \& Pollard, J. A. (n.d.). Item-construct dictionary for Student Survey of Rick and Protective Factors and prevalence of alcohol, tobacco, and other drug use. Seattle, WA: Social Development Research Group, University of Washington.

Corcoran, K. (2005). The Oregon Mental Health Referral Checklist: Concept mapping the mental health needs of youth in the juvenile justice system. Brief Treatment and Crisis Intervention, 5, 9-18.

DeMatteo, D., \& Marczyk, G. (2005). Risk factors, protective factors, and the prevention of antisocial behavior among juveniles. In $\mathrm{K}$. Heilbrun, N. E. Seven Goldstein, \& R. E. Redding (Eds.), Juvenile delinquency: Prevention, assessment, and intervention (pp. 19-44). New York: Oxford University Press.

Federal Bureau of Investigation. (2000). Crime in the United States, 2000. Washington, DC: Author.
Gottfredson, M., \& Hirschi, T. (1990). A general theory of crime. Palo Alto, CA: Stanford University Press.

Hair, J. F., Black, W. C., Babin, B. J., Anderson, R. E., \& Tatham, R. L. (2005). Multivariate data analysis (6th ed.). Upper Saddle River, NJ: Prentice Hall.

Hawkins, J. D., Herrenkohl, T. L., Farrington, D. P., Brewer, D., Catalano, R.F., Harachi, T. W. et al. (2000). Predictors of youth violence. Washington, DC: U.S. Department of Justice, Office of Juvenile Justice and Delinquency Prevention.

Hirschi, T. (1969). Causes of delinquency. Berkeley, CA: University of California Press.

Martin, E. J., Tobin, T. J., \& Sugai, G. M. (2002). Current information on dropout prevention: Ideas from practitioners and the literature. Preventing School Failure, 47(1), 10-18.

McNeece, C. A., Bullington, B., Arnold, E. M., \& Springer, D. W. (2005). The war on drugs. Treatment, research, and substance abuse intervention in the twenty-first century. In R. Muraskin \& A. R. Roberts (Eds.), Visions for change: Crime and justice in the twenty-first century (4th ed., pp. 88-120). Upper Saddle River, NJ: Prentice Hall.

Myer, R. A. (2001). Assessment for crisis intervention: A triage assessment model. Belmont, CA: Wadsworth.

Myer, R. A., Williams, R. C., Ottens, A. J., \& Schmidt, A. E. (1992). Crisis assessment: A three dimensional model for triage. Journal of Mental Health Counseling, 14, 137-148.

Office of Juvenile Justice and Delinquency Prevention. (1999). Juvenile offenders and victims: 1999 national report. Washington, DC: Author.

Springer, D. W. (1998). Validation of the Adolescent Concerns Evaluation (ACE): Detecting indicators of runaway behavior in adolescents. Social Work Research, 22, 241-250.

Springer, D. W. (2000). Adolescent Concerns Evaluation (ACE). In K. Corcoran \& J. Fischer (Eds.), Measures for clinical practice. Volume I: Couples, families and children (3rd ed., pp. 449453). New York: Free Press. 
Springer, D. W. (2001). Runaway adolescents: Today's Huckleberry Finn crisis. Brief Treatment and Crisis Intervention, 1, 131-151.

Synder, H. N. (2000). Juvenile arrests 1999. Washington, DC: U.S. Department of Justice, Office of Juvenile Justice and Delinquency Prevention.

Synder, H. N. (2002). Juvenile arrests 2000. Washington, DC: U.S. Department of Justice, Office of Juvenile Justice and Delinquency Prevention.
Teplin, L. A., Abram, K. M., McClelland, G. M., Duclan, M., \& Mericle, A. A. (2003). Psychiatric disorders in youth in juvenile detention. Archives of General Psychiatry, 59, 1133-1143.

Thompson, S. J., McManus, H., \& Voss, T. (2006). Posttraumatic stress disorder and substance abuse among youth who are homeless: Treatment issues and implications. Brief Treatment and Crisis Intervention, 6, 206-217. Warr, M. (2002). Companions in crime. Cambridge, UK: Cambridge University Press. 